\title{
Gingival Recession Coverage Using Free Gingival Autograft- A Case Report
}

\author{
Priya Lele, ${ }^{1}$ Tanya Satyapal, ${ }^{2}$ Ripple Mahagaonkar, ${ }^{3}$ Vishakha Patil, ${ }^{4}$ \\ Rohini Mali ${ }^{5}$ \\ Department of Periodontology,Bharati Vidyapeeth Deemed University Dental College And Hospital, \\ Pune,India
}

\begin{abstract}
Gingival recession results in a cosmetic deficit and may also affect function. The main indications for root coverage procedures are progressive gingival recession, esthetic demands and root sensitivity. Coverage of denuded roots is one of the most challenging procedures in periodontal mucogingival surgery. Various surgical options have been developed to achieve the root coverage and include the use of free gingival autograft (FGG), subepithelial connective tissue graft, laterally sliding flap, coronally advanced flap, double papilla flap, guided tissue regeneration etc. FGG is a procedure of high degree of predictability when used alone or combined with other technique. However it is technically demanding, time consuming, and the color match of the tissue is often less than ideal. A 25 year old male patient reported with the chief compliant of receding gum and root sensitivity in a lower front tooth (Miller's Class II gingival recession with 41). Free gingival autograft was carried out with 41 and complete recession coverage was achieved. Despite the fact that other effective root coverage techniques have been developed, the free gingival graft may still be the best treatment option when recession coverage with an increase in the apicocoronal dimension of the keratinized gingival tissues is the desired treatment outcome.
\end{abstract}

Key words: Gingival recession, root sensitivity, root coverage, mucogingival surgery, free gingival autograft $(F G G)$

\section{Introduction}

A significant factor associated with the success of dental therapy is physiologic well being of the patient. Gingival recession according to the glossary of Periodontal terms is defined as "Displacement of the soft tissue margin apical to the cemento-enamel junction". [1] Etiologicfactors for gingival recession include plaque induced periodontal inflammation, traumatic tooth brushing, tooth malposition, high frenal attachment, orthodontic tooth movement, oral jewellery etc. The primary indications for recession coverage include teeth with progressive recession, esthetic considerations, c/o root hypersensitivity . Various surgical options have been developed to achieve the root coverage. These include the use of free soft tissue grafts ( free gingival graft -FGG, subepithelialconnective tissue graft), pedicle soft tissue flaps ( rotational and advanced flaps laterally sliding flap, coronally advanced flap, double papilla flap ) and guided tissue regeneration. The term FGG was introduced by Nabers in 1966, when he used the gingival tissue discarded after a gingivectomy as the donor tissue. [2] Later, Pennel et al in 1969 used the masticatory mucosa as the donor tissue and the technique is still in use. [3] FGG, used both as a two-step procedure (Bernimoulin et al 1975) - or a one step procedure (P.D. Miller 1982), for the coverage of denuded roots, is a versatile modality of treatment and can be used in a variety of clinical situations. [4,5] Problem areas presenting with a lack of keratinized tissue and gingival recession can be effectively treated with the free gingival graft to create an adequate zone of attached gingiva and coverage of the exposed root. Areas of gingival recession, in the absence of a mucogingival problem, in which there is an aesthetic or root sensitivity consideration, can be also treated with a free gingival graft. [6]

\section{Case Report}

A 25 year old male patient reported to the department of Periodontology, Bharati Vidyapeeth Dental College \& Hospital, Pune with the chief compliant of root sensitivity and receding gum in lower front region since 5-6 months. The patient was medically fit. He gave history of use of a hard toothbrush and horizontal strokes during brushing. Intraoral clinical examination revealed slight crowding and rotation of lower anterior teeth. Gingival recession was evident with 41. It was diagnosed as Class II recession according to Miller's classification. [7] Phase I therapy was carried out and the patient was advised to use a soft toothbrush with modification of brushing technique. On recall after one month gingival recession measuring $5 \mathrm{~mm}$ apicocoronally and $2 \mathrm{~mm}$ mesiodistally with 41 was seen (Fig. 1). An IOPA radiograph of the lower anterior region showed no evidence of interdental bone loss. One step technique of FGG to achieve recession coverage 
was planned. The procedure was explained to the patient and an informed written consent was obtained for surgery.

\subsection{Surgical Procedure: Preparation of Recipient Bed}

Local anesthesia was achieved using lidocaine hydrochloride2\% and 1:200,000 adrenaline. The exposed root of 41 was planed thoroughly with a Gracey 1-2 curette. A horizontal incision was made at the level of cemento-enamel junction extending from the line angle of adjacent teeth on either side of the recession. Two vertical incisions were made, on either end of the horizontal incision, extending well into the alveolar mucosa. A deep split thickness dissection was performed to achieve a recipient site with butt joints against all keratinized gingiva. (Fig.2). Thus a recipient bed measuring approximately $10 \mathrm{~mm} \times 12 \mathrm{~mm}$ was prepared.

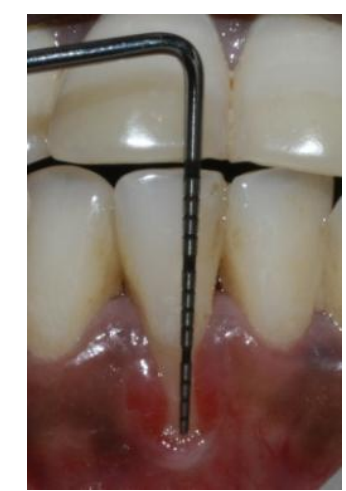

Figure 1- Presurgical view

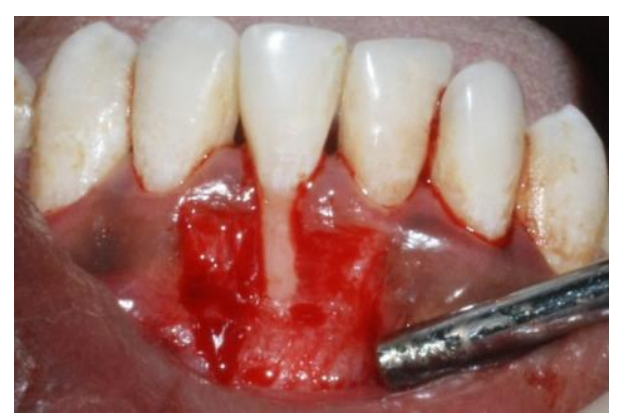

Figure 2: Preparation of recipient bed

\subsection{Preparation of Donor Tissue:}

The amount of donor tissue needed was accurately determined by using a foil template. The palatal site between premolars and the first molar was selected to harvest the donor tissue using the conventional technique. The initial incisions were outlined by the placement of tinfoil template with a no. 15 scalpel blade. Care was taken to place the incision $2 \mathrm{~mm}$ from the palatal gingival margin to prevent recession on these teeth. Incisions were made in such a fashion as to create the butt joint margin in the donor tissue. The incision was made along the occlusal aspect of the palate with no. 15 scalpel blade held parallel to the tissue, continued apically, lifting and separating the graft. Tissue pliers were used to retract the graft distally as it was being separated apically and dissected, until the graft was totally freed. The graft obtained was inspected for any glandular or fatty tissue remnants. The thickness of the graft was approximately $1.5 \mathrm{~mm}$ (Fig.3). The palatal wound was protected by a Hawley's retainer.

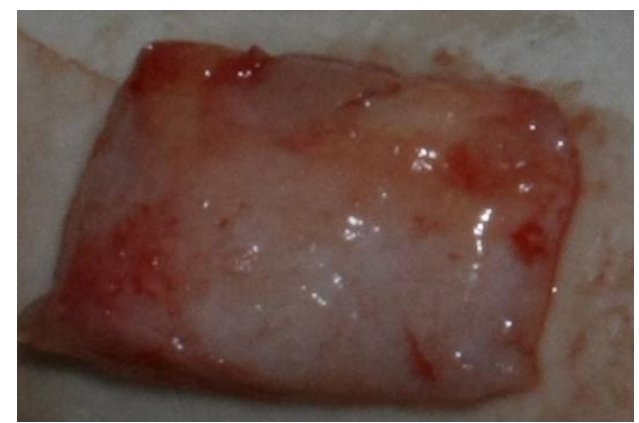

Figure 3: Free gingival graft harvested from palate 


\subsection{Graft placement and stabilization.}

The graft was placed on the recipient bed and sutured by means of interrupted sutures (6- 0 vicryl) at the coronal and apical borders. A horizontal stabilizing suture and a vertical pressure suture were given for close adaptation of the graft to the tooth surface (Fig 4).

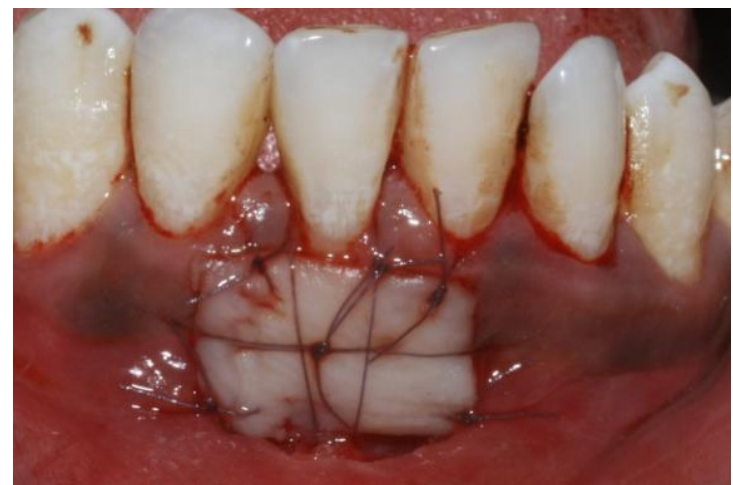

Figure 4 : Graft sutured to the recipient bed

\subsection{Post Operative Instructions:}

The patient was asked to refrain from tooth brushing at the surgical site for two weeks. Oral hygiene instructions included mouth rinses with $10 \mathrm{ml}$ of $0.12 \%$ chlorhexidine digluconate mouthwash twice daily for 1 minute for two weeks Capsule Amoxicillin 500mg thrice daily and Tablet Diclomol twice daily for 3 days were prescribed. Patient was recalled after 10 days for suture removal.

After 10 days, the grafted region was gently cleaned with a cotton pellet dipped in normal saline and hydrogen peroxide and sutures were removed. The graft was pink and healthy. The healing of palatal wound was satisfactory. The patient was instructed to use a soft tooth followed by a 60 -second rinse with chlorhexidine digluconate for the next 6 weeks. Fig. 5 shows the operated site at one month recall.

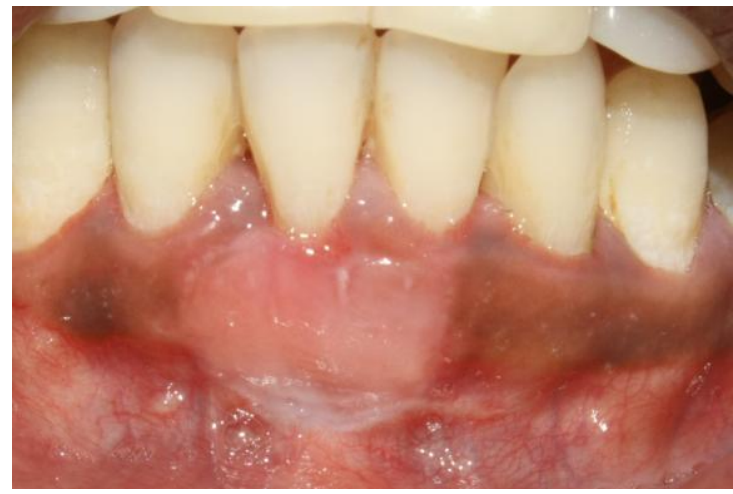

Figure 5: One month postoperative view

\section{Discussion}

Root coverage by placing free graft was described by Sullivan and Atkins and they reported that free gingival graft offers best results in cases of shallow and narrow recession. [8] Later Miller (1985) described a useful classification of recession defects taking into consideration the anticipated root coverage that is possible to obtain.[7] This case report presented Miller's class-II recession of tooth no 41, in which complete root coverage by free autogenous soft tissue graft could be achieved. Miller's criteria for successful root coverage include: the soft tissue margin must be at the cemento-enamel junction, clinical attachment to the root, with sulcus depth of $2 \mathrm{~mm}$, and no bleeding on probing. [4] Thick $(1.5-2+\mathrm{mm})$ free epithelialized autogenous soft tissue grafts are recommended for recession coverage. [9] Although these have a greater primary contraction as compared to the thin $(0.5-0.8 \mathrm{~mm})$ or average $(0.9-1.4 \mathrm{~mm})$ thickness grafts, their secondary contraction is less during the healing process. The thick grafts are more resistant to future recession. Also with thick grafts which replace the gingival margin, the process of creeping attachment is frequently seen. With creeping attachment, an increase in root coverage of approximately $1 \mathrm{~mm}$ over a 1 year period post surgery usually occurs. [10] However these are more technically demanding, time consuming, and the color match of the tissue is often less than ideal. Due to the predictability and versatility of connective tissue graft, the use of the free gingival graft for root coverage has drastically declined. But FGG is best suited in the 
following situations: increasing the depth of vestibule, increasing the amount of attached gingiva associated with a restoration, augmenting the area of minimal gingiva prior to orthodontic treatment.

\section{Conclusion}

The free gingival graft for root coverage is still a viable and effective modality of mucogingival surgery. Despite the fact that other effective root coverage techniques have been developed, the free gingival graft may still be the best treatment option for gingival recession when an increase in the apicocoronal dimension of the keratinized gingival tissues is a desirable treatment. Close attention to proper case diagnosis and to the steps involved in the surgical procedure are crucial in maximizing the predictability of the free gingival graft in correcting mucogingival problems and achieving root coverage.

\section{References}

[1] Glossary of Periodontal Terms

[2] Nabers C L. Free gingival grafts Periodontics 1966, 4, 244-245.

[3] Pennel B M, Tabor J C, King K O et al. Free masticatory mucosa graft J Periodontol 1969, 40,16c2

[4] Bernimoulin J P, Luscher Band, Muhlemann H R Coronally repositioned periodontal flap. Clinical evaluation after one year. Journal of Clinical Periodontology 1975, 2, 1-13

[5] Miller PD. Root coverage using a free soft tissue autograft following citric acid application. I. Technique. International Journal of Periodontics \& Restorative Dentistry 1982, 2, 65-70.

[6] Paulo M. Camargo, philip R. Melnick \&e. Barrie Kenney. The use of free gingival grafts for aesthetic purposes. Periodontology 2000, 2001, Vol. 27, 72-96.

[7] Miller PD A classification of marginal tissue recession. International Journal of Periodontics \& Restorative Dentistry 1985, 5, 913.

[8] Sullivan H, Atkins J. Free autogenous gingival grafts. Utilization of grafts in the treatment of gingival recession. Periodontics1968; 6(4):152.

[9] Holbrook T, Ochsenbein C Complete coverage of the denuded root surface with a one stage gingival graft International Journal of Periodontics \& Restorative Dentistry 1983,3, 8-27

[10] Matter J, Cimasoni G Creeping attachment after free gingival grafts J Periodontol 1976, 47, 574-579 